\title{
ERP selection: A step-by-step application of AHP Method
}

\author{
Noureddine Motaki \\ Laboratory LTI \\ ENSA of Tangier \\ Tangier, Morocco
}

\author{
Oualed Kamach \\ Laboratory LTI \\ ENSA of Tangier \\ Tangier, Morocco
}

\begin{abstract}
A successful implementation of an ERP project in an organization requires the selection of a suitable ERP system. Indeed, the selection of an ERP system has a significant effect on future operations and profitability of the enterprise.

Many research works identified major factors influencing the selection of an ERP in SMEs, and proposed criteria and methods related to the optimization of the selection process.

Several ERPs selecting methods use AHP, on one hand in order to determine the weight of the criteria, and on the other hand to evaluate ERP systems. Some methods use only AHP, where other methods use a combination of AHP with other Multi decision criteria Methods (hybrid methods).

The first objective of this paper is to present a review of literature on ERP selection process: after describing the methods used to select the ERP systems, the criteria list that companies use to select their ERP systems is presented.
\end{abstract}

The second objective is to propose a detailed example of using the AHP method in an ERP selection context, a step-bystep application of AHP will be demonstrated.

\section{Keywords}

ERP, Selection, criteria, Process, AHP

\section{INTRODUCTION}

Companies need to increase productivity, shorten lead times, reduce stock, maximize return on investment, reduce total costs, and have a better communication with customers and suppliers.

Enterprise Resource Planning (ERP) is very important to help companies achieve these goals because of its ability to integrate the flow of information, material, and finance, and to support organizational strategies. An ERP system integrates all necessary business functions, such as purchasing, sales, product planning, financial, inventory control, through modules that share a single database. However, given the diversity of the business processes and the sector of activity of each company, there is no ERP commercial packages can meet all company functionalities or all special business requirements. Thus, it is necessary to select a suitable ERP system that can meet the needs of the company and its organizational requirements.

Recent studies show that the majority of ERP projects do not end in success. One of the most common reasons that can lead to this failure is the selection phase study [1]. The selection of a particular ERP system has a decisive effect on the future operations and profitability of the enterprise, this is why the applied selection criteria for ERP systems and the method used should be analyzed very carefully.
Several methods have been applied to ERP selection including scoring, ranking, mathematical optimization, and multi-criteria decision analysis.

The analytic hierarchy process (AHP) method is applied for dealing with the ambiguities involved in the assessment of ERP alternatives and relative importance weightings of criteria. To apply AHP, weights of the criteria are determined after the consultation session realized by the selection team. To determine weights of the criteria in the AHP hierarchy, each criterion is compared using a pairwise comparison method with respect to their immediate higher-level criteria in the hierarchy. According to Saaty, quantitative or qualitative assessments can be used in the comparisons: a nine-point numerical scale, is recommended for the comparisons.

In this paper a step-by-step application of AHP Method will be demonstrated.

\section{STATE OF THE ART}

In literature, several evaluation models have been proposed to improve the selection process of an ERP. A part of these methods has a theoretical foundation based in mathematic programming and decision theories: multi-criteria decisionmaking methods (MCDM) are used to prioritize alternatives and calculate the relative efficiencies of ERP solutions. Other methods have focused on identifying success factors in ERP selection process [2].

The review of the state of the art on ERP selection Methods revealed the following methods: AHP (Analytic Hierarchy Process), ANP (Analytic Network Process) [3], [4], [5], [6], [7] PROMETHEE [8], SHERPA (Systematic Help ERP Acquisition), FL (Fuzzy Logic) [9], PM (Priority Matrix), TOPSIS (Technique for Order Preference by Similarity to Ideal Solution) [6]

\subsection{AHP Method}

Introduced by Saaty (1980), The AHP method directs how to determine the priority of a set of alternatives and the relative importance of attributes in a multiple criteria decision-making problem,

This method has been widely discussed in various studies:

The ERP selection method proposed by Wei, Chien and Wang is based on AHP method and presented in seven steps [10]. The AHP and ANP methods are discussed in the literature, and some applications of these methods are described in research papers. [11], [12].

Ünal and Güner proposed a methodology based on AHP for ERP provider selection for an organization in the textile industry [13]. In the same sector, Cebeci presented another ERP supplier selection methodology based on fuzzy AHP [14]. An illustrative example of the application of fuzzy AHP 
was also carried out for the selection of ERP outsourcing alternatives [15].

Numerous studies are successfully combined more than one multi-criteria decision-making methods (hybrid methodology): A research paper describes a decision-making model using a combination of quality function deployment (QFD), fuzzy linear regression and AHP [16]. Kilic, Zaim, and Delen proposed another hybrid methodology; they used fuzzy AHP and TOPSIS for the ERP selection for an airline company. [4]

Burak Efe used an integration of fuzzy AHP and fuzzy TOPSIS (technique for order preference by similarity to ideal solution), an application case is performed on the ERP selection software of an electronic firm. In this application, the priority values of criteria in ERP selection have been determined by using fuzzy extension of AHP method. The result of the fuzzy TOPSIS model have been used to define the most appropriate alternative with regard to the firm goals. [17]

Maria Manuela Cruz-Cunha presented an AHP model for the selection of ERP system. The model's set of criteria was extracted from the literature review and validated by Portuguese organizations. They applied this model using a software that eases the application of the AHP process to the selection of ERP packages [18].

\subsection{ERP Selection Criteria}

The life cycle of the ERP system consists of three main phases: the selection phase (selection of the product, vendor and consultant), the implementation phase (functional and technical implementation), and the phase of use (from the Go live step). The selection process plays an important role in the success or failure of the ERP project: a wrong selection of the ERP system would either fail the project or critically reduce the system and hinder the performance of the organization.

The ERP research papers have suggested several ERP selection criteria. As presented in the literature, the selection criteria for an ERP can be organized around the following categories [19], [4], [20], [21], [22], [1]:

- Functional criteria

- Technical criteria

- The criteria for the vendor

- The criteria for services provided

- Partners Criteria

- Financial criteria

- Implementation phases criteria

\subsubsection{Functional criteria:}

\subsubsection{ERP compatibility with the enterprise} business processes:

It is the most important evaluation factor in the ERP selection process, in order to validate this phase, ERP systems must satisfy the following conditions:

$\checkmark$ The ERP systems should have adequate or even more modules related to the organization main activities.

$\checkmark$ The ERP systems should support the critical business processes.

\subsubsection{The ERP system must incorporate best} practices:

The ERP reflects the vendor's interpretation of the most efficient way to perform each enterprise business process; the ERP modules must to be based on the management best practices, for business process and for industry areas.

\subsubsection{Technical criteria:}

2.2.2.1 New trends in the IT industry:

The ERP compatibility with the latest trends in IT.

\subsubsection{Ease of integration and compatibility} with other systems:

The compatibility and the integration with other systems is a determining criterion for the selection of the ERP. Indeed, most of the organizations are using independent and indispensable software like CRM, SRM. the ERP system must be able to connect and communicate with these products. From this perspective, compatibility and integration with other systems are considered as a crucial criterion for selecting the ERP solution.

\subsubsection{Modules independency:}

The ERP system should be module-independent, where organizations are free to choose the modules they need only.

\subsubsection{The ERP ability to integrate different platforms and data:}

This criterion evaluates the complexity of data migration from an old information system to the newly installed ERP, and evaluate also the transition from classical office programs to ERP system.

\subsubsection{System stability:}

The tendency of the system to be more stable.

\subsubsection{Flexibility:}

Flexibility of the ERP with the future needs of the company and the possible modifications of the business processes.

\subsubsection{The criteria for the vendor (ERP Provider):}

Vendor position in the ERP market and its experience in the ERP systems, Brand image, References...

\subsubsection{The Criteria for services provided:}

\subsubsection{Maintainability and support from} vendors:

The majority of organizations require maintainability and support from suppliers to face technical problems, security issues and integration difficulties with the application during the whole implementation process and after the go live phase.

\subsubsection{Training:}

A training program for users is essential before the go live phase.

\subsubsection{Partner Criteria:}

\subsubsection{Consultant's suggestions:}

The expertise of consultants in ERP implementation projects and their recommendations can be considered among the most important factors in the ERP selection process. 
ERP systems used by partners (customers and suppliers):

The tendency to have similar or compatible ERPs is important: EDIs are often used to ensure interconnection between partner ERPs.

\subsubsection{Benchmarking:}

The level of the ERP use by competing enterprises or enterprises whose business sector is the same.

\subsubsection{Financial criteria:}

This criterion contains the cost types of ERP implementation project, including product-licensing cost, ERP implementation cost, support service and training costs, organizational change management cost $(\mathrm{OCM})$

\subsubsection{Implementation phases criteria:}

\subsubsection{Complexity of using ERP:}

This criterion evaluates the complexity of understanding and use of ERP by end users, key users and managers. ERPs can be distinguished according to the usability of the user interfaces and the ergonomic rules applied.

\subsubsection{The duration and complexity of ERP implementation:}

The implementation phase of an ERP can take weeks, even months, depending on the number of modules to be integrated, the complexity of the business processes and the implementation methodology.

\section{APPLICATION}

In this part, the AHP method will be applied to determine the best ERP according to the criteria that will be determined later.

Before applying the AHP method, a set of the ERP selection phases must be performed by the project team, the list of proposed selection phases is presented as follows:

$\checkmark$ Define the evaluative criteria used to select the suitable ERP supplier.

$\checkmark \quad$ Define the ERP shortlist.

$\checkmark \quad$ Establish the AHP Model.

$\checkmark$ Application of the AHP Method

Phase 1: Define the evaluative criteria used to select the suitable ERP supplier:

The ERP selection team is responsible for determining the selection criteria according to the constraints of the enterprise and the advice of the external consultants.

The criteria should be discussed with the company managers. According to these discussions the criteria are determined. In this example the following criteria will be used:

$\checkmark$ Adaptability criteria (C1)

$\checkmark \quad$ Financial criteria (C2).

$\checkmark$ Simplicity criteria (C3).

$\checkmark$ Provider services (C4)

$\checkmark$ Implementation approach (C5).

each of the above criteria has been decomposed into several sub-criteria to better understand the meaning of each criterion. the sub-criteria have been given only for information, they will not be taken into consideration in the various calculations carried out by applying the AHP method. otherwise the AHP method proposes directives which allow the weights of each sub-criterion to be calculated using the local pairwise comparisons and the weights of the criteria already calculated. the following table shows the decomposition of each criterion into sub-criteria.

Table 1. Sub-criteria

\begin{tabular}{|l|l|}
\hline \multicolumn{1}{|c|}{ Criterion } & \multicolumn{1}{|c|}{ Sub-criteria } \\
\hline Adaptability & $\begin{array}{l}\text { - Compatibility with the enterprise } \\
\text { business processes. } \\
\text { - Technical constraints. } \\
\text { - System features } \\
\text { - Ability to integrate company platforms } \\
\text { and data. }\end{array}$ \\
\hline Financial & $\begin{array}{l}\text { - Service \& support cost. } \\
\text { - Product License. }\end{array}$ \\
& $\begin{array}{l}\text { - Implementation cost } \\
\text { - Budget of the company }\end{array}$ \\
\hline Simplicity & $\begin{array}{l}\text { - Ease of use } \\
\text { - Ergonomic software } \\
\text { - Complexity system }\end{array}$ \\
\hline Provider services & $\begin{array}{l}\text { - Maintainability from provider } \\
\text { - Support from provider } \\
\text { - Training }\end{array}$ \\
\hline Implementation & $\begin{array}{l}\text { - The duration of ERP implementation } \\
\text { - The complexity of implementation } \\
\text { - Successful references }\end{array}$ \\
\hline
\end{tabular}

Phase 2: Define the ERP shortlist.

in a ERP selection project, the selection team should identify key business challenges that the enterprise aims to solve with the ERP system, gather the requirement of each department, and identify the ERP system characteristics.

Another task of the team is the collection of the possible information about the ERP systems and the vendors, and create an initial shortlist of vendors.

To obtain the ERP shortlist, the selection team should identify ERP solutions specific to the company industry, and research the ERP system employed by similar companies.

an ERP selection team must have among its members an expert consultant with extensive experience in ERP projects as well as a clear vision of all the ERP solutions of the market, its characteristics and its technical and functional specifications. this consultant, in collaboration with the different members of the team, can propose an initial list of ERP systems.

In this example the shortlist is composed of two of ERP systems that called ERP A and ERP B.

\section{Phase 3: Establish the AHP Model:}

Hierarchical model of problem is composed according the criteria below (step 1). Level one represents the goal, which is to select the suitable ERP provider. The second level represents selection criteria, followed by the alternatives in the third level. (fig1) 


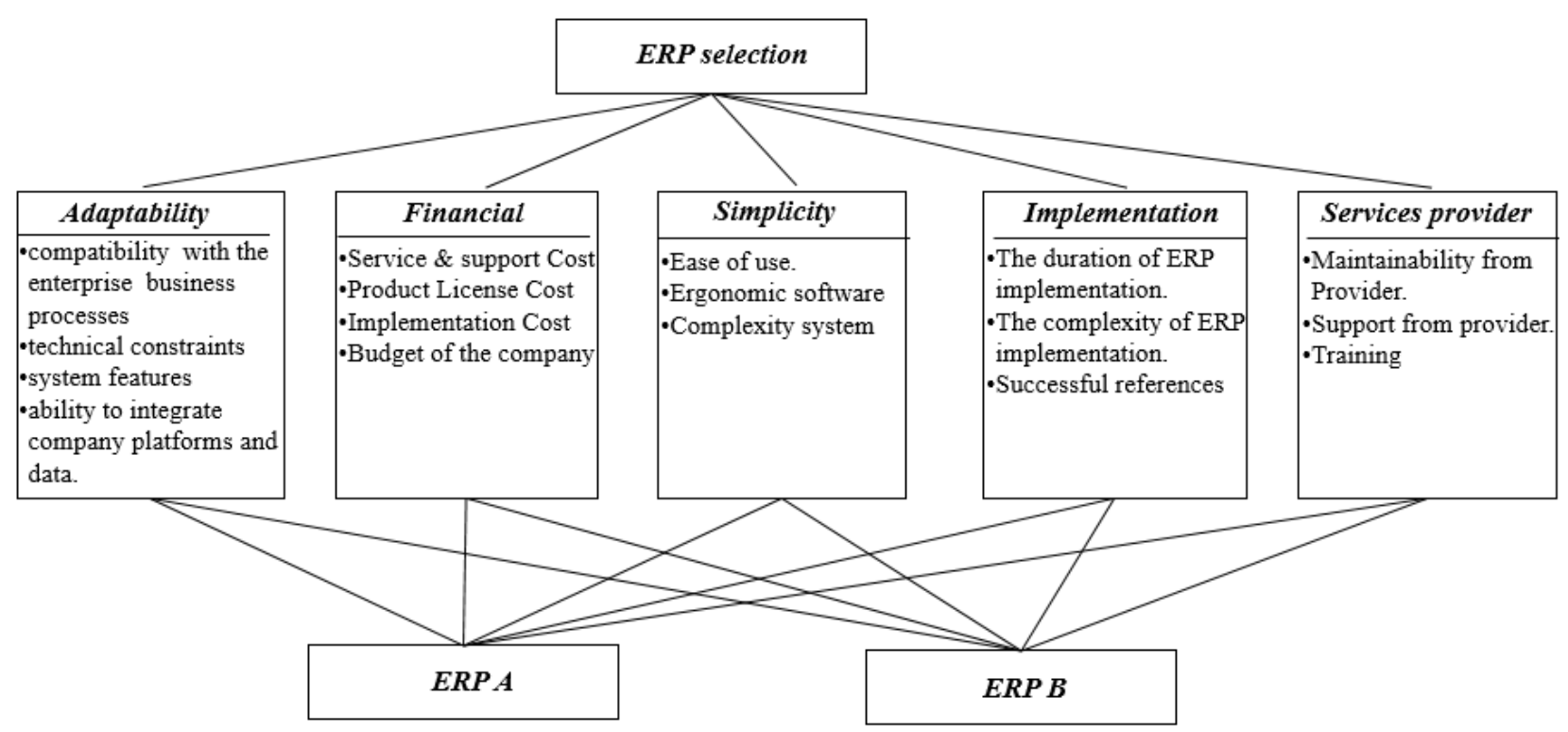

Fig 1: AHP Model

\section{Phase 4: Application of the AHP Method}

Each criterion will be evaluated compared to the others. Usually, this step is obtained based on the views of the selection team (following discussions at project team meetings). For example: Adaptability is more important than simplicity with 5 points(fig.2).

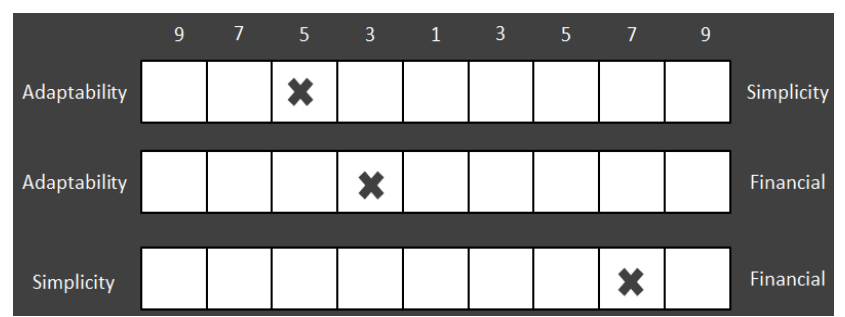

Fig 2: The pairwise comparison

Based on the evaluations of previous step, we build the pairwise comparison matrix according to the following rule:

$$
a_{i j}>0, \quad a_{j i}=\frac{1}{a_{i j}}, \quad a_{i i}=1
$$

The value of the $(i, j)$ position of the pairwise comparison matrix is determined using Saaty's scale $(1,3,5,7,9)$, the inverse value of the assigned number is assigned to the ( $\mathrm{j}, \mathrm{i}$ ) position (fig.3).

Table 2. The pairwise comparison matrix

\begin{tabular}{|c|c|c|c|c|c|}
\hline Criteria & $\mathrm{C} 1$ & $\mathrm{C} 2$ & $\mathrm{C} 3$ & $\mathrm{C} 4$ & $\mathrm{C} 5$ \\
\hline $\mathrm{C} 1$ & $\mathbf{1}$ & $\mathbf{3}$ & $\mathbf{7}$ & $\mathbf{5}$ & $\mathbf{3}$ \\
\hline $\mathrm{C} 2$ & $\mathbf{1 / 3}$ & $\mathbf{1}$ & $\mathbf{7}$ & $\mathbf{5}$ & $\mathbf{3}$ \\
\hline
\end{tabular}

\begin{tabular}{|c|c|c|c|c|c|}
\hline $\mathrm{C} 3$ & $1 / 7$ & $1 / 7$ & 1 & $1 / 3$ & $1 / 3$ \\
\hline $\mathrm{C} 4$ & $1 / 5$ & $1 / 5$ & 3 & 1 & $1 / 3$ \\
\hline $\mathrm{C} 5$ & $1 / 3$ & $1 / 3$ & 3 & 3 & 1 \\
\hline
\end{tabular}

In order to obtain the weight of each criterion, the following instructions are used:

First, the sum of each column is calculated, then the normalization of the matrix by dividing the content of each cell by the Sum of its column, and finally calculation of the average of the rows (Table 2, Table 3 and Table 4) :

Table 3. The sum of columns

\begin{tabular}{|c|c|c|c|c|c|}
\hline Criteria & $\mathrm{C} 1$ & $\mathrm{C} 2$ & $\mathrm{C} 3$ & $\mathrm{C} 4$ & $\mathrm{C} 5$ \\
\hline $\mathrm{C} 1$ & $\mathbf{1}$ & $\mathbf{3}$ & $\mathbf{7}$ & $\mathbf{5}$ & $\mathbf{3}$ \\
\hline $\mathrm{C} 2$ & $\mathbf{1 / 3}$ & $\mathbf{1}$ & $\mathbf{7}$ & $\mathbf{5}$ & $\mathbf{3}$ \\
\hline $\mathrm{C} 3$ & $\mathbf{1 / 7}$ & $\mathbf{1 / 7}$ & $\mathbf{1}$ & $\mathbf{1 / 3}$ & $\mathbf{1 / 3}$ \\
\hline $\mathrm{C} 4$ & $\mathbf{1 / 5}$ & $\mathbf{1 / 5}$ & $\mathbf{3}$ & $\mathbf{1}$ & $\mathbf{1 / 3}$ \\
\hline $\mathrm{C} 5$ & $\mathbf{1 / 3}$ & $\mathbf{1 / 3}$ & $\mathbf{3}$ & $\mathbf{3}$ & $\mathbf{1}$ \\
\hline $\begin{array}{l}\text { Sum of } \\
\text { column }\end{array}$ & $\mathbf{2 , 0 1}$ & $\mathbf{4 , 6 8}$ & $\mathbf{2 1 , 0 0}$ & $\mathbf{1 4 , 3 3}$ & $\mathbf{7 , 6 7}$ \\
\hline
\end{tabular}

Table 4. Normalized pairwise comparison matrix

\begin{tabular}{|c|c|c|c|c|c|}
\hline Criteria & C1 & C2 & C3 & C4 & C5 \\
\hline C1 & $\mathbf{0 , 5 0}$ & $\mathbf{0 , 6 4}$ & $\mathbf{0 , 3 3}$ & $\mathbf{0 , 3 5}$ & $\mathbf{0 , 3 9}$ \\
\hline
\end{tabular}




\begin{tabular}{|c|c|c|c|c|c|}
\hline C2 & $\mathbf{0 , 1 7}$ & $\mathbf{0 , 2 1}$ & $\mathbf{0 , 3 3}$ & $\mathbf{0 , 3 5}$ & $\mathbf{0 , 3 9}$ \\
\hline $\mathrm{C} 3$ & $\mathbf{0 , 0 7}$ & $\mathbf{0 , 0 3}$ & $\mathbf{0 , 0 5}$ & $\mathbf{0 , 0 2}$ & $\mathbf{0 , 0 4}$ \\
\hline $\mathrm{C} 4$ & $\mathbf{0 , 1 0}$ & $\mathbf{0 , 0 4}$ & $\mathbf{0 , 1 4}$ & $\mathbf{0 , 0 7}$ & $\mathbf{0 , 0 4}$ \\
\hline C5 & $\mathbf{0 , 1 7}$ & $\mathbf{0 , 0 7}$ & $\mathbf{0 , 1 4}$ & $\mathbf{0 , 2 1}$ & $\mathbf{0 , 1 3}$ \\
\hline
\end{tabular}

Table 5. Calculation of criteria's weight

\begin{tabular}{|c|c|c|c|c|c|c|c|}
\hline Criteria & C1 & C2 & C3 & C4 & C5 & $\begin{array}{l}\text { Sum of } \\
\text { line }\end{array}$ & Weight \\
\hline C1 & 0,50 & 0,64 & 0,33 & 0,35 & 0,39 & $\mathbf{2 , 2 1}$ & $\mathbf{0 , 4 4}$ \\
\hline C2 & 0,17 & 0,21 & 0,33 & 0,35 & 0,39 & $\mathbf{1 , 4 5}$ & $\mathbf{0 , 2 9}$ \\
\hline C3 & 0,07 & 0,03 & 0,05 & 0,02 & 0,04 & $\mathbf{0 , 2 2}$ & $\mathbf{0 , 0 4}$ \\
\hline C4 & 0,10 & 0,04 & 0,14 & 0,07 & 0,04 & $\mathbf{0 , 4 0}$ & $\mathbf{0 , 0 8}$ \\
\hline C5 & 0,17 & 0,07 & 0,14 & 0,21 & 0,13 & $\mathbf{0 , 7 2}$ & $\mathbf{0 , 1 4}$ \\
\hline
\end{tabular}

Conclusion: Adaptability is the most important criterion with a 0.44 weight, then comes financial criterion with 0.29 weight, the third criterion is the implementation approach with a 0,14 weight, then comes provider services criterion with a weight of 0,08 and the last one is simplicity criterion with a weight of 0.04 .

\section{Consistency check:}

Before proceeding to the next step of the AHP method, it is essential to make sure that we did not make any absurd comparisons and that criteria weights are indeed consistent, that's why this step is mostly important, to check the system consistency it is necessary to follow the steps below:

$\begin{array}{ll}\checkmark & \text { Calculate Weight sums vector: } \quad\{\mathrm{Ws}\}=\{\mathrm{M}\} \cdot\{\mathrm{W}\} \\ \checkmark & \text { Find the Consistency vector: } \quad\{\mathrm{Cv}\}=\{\mathrm{Ws}\} \cdot\left\{\frac{1}{W}\right\}\end{array}$

$\checkmark \quad$ Average Consistency vector, this quantity is called $\lambda \max$.

$\checkmark$ Determinate Consistency Index $C I=\frac{\left(\lambda_{\max }-n\right)}{(n-1)}$

$\checkmark \quad$ Calculate Consistency ratio :

$$
C R=\frac{C I}{R I}
$$

The RI or Random Index is obtained from the table below, the first row represents the number of criteria (n):

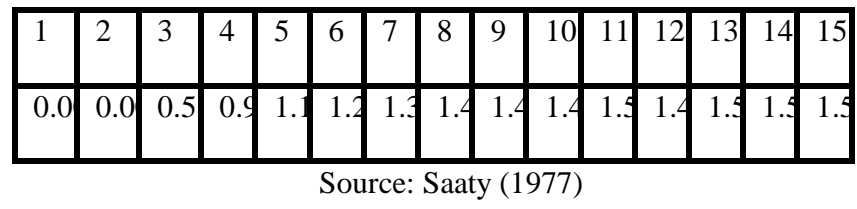

The final test is:

If $\mathrm{CR}<0,1$ : then the matrix is consistent and judgments can be considered coherent.

If $\mathrm{CR}>0,1$ : then the matrix results are inconsistent and were exempted for the further analysis.

The next step is to check the results of the previous example:

$\checkmark \quad$ First the Weight sums vector Ws will be determined:

$$
\left(\begin{array}{c}
2,45 \\
1,57 \\
0,22 \\
0,40 \\
0,76
\end{array}\right)=\left(\begin{array}{ccccc}
\mathbf{1} & \mathbf{3} & \mathbf{7} & \mathbf{5} & \mathbf{3} \\
\mathbf{1} / \mathbf{3} & \mathbf{1} & \mathbf{7} & \mathbf{5} & \mathbf{3} \\
\mathbf{1} / \mathbf{7} & \mathbf{1} / \mathbf{7} & \mathbf{1} & \mathbf{1 / 3} & \mathbf{1} / \mathbf{3} \\
\mathbf{1} / \mathbf{5} & \mathbf{1 / 5} & \mathbf{3} & \mathbf{1} & \mathbf{1} / \mathbf{3} \\
\mathbf{1} / \mathbf{3} & \mathbf{1 / 3} & \mathbf{3} & \mathbf{3} & \mathbf{1}
\end{array}\right)\left(\begin{array}{c}
0,44 \\
0,29 \\
0,04 \\
0,08 \\
0,14
\end{array}\right)
$$

$\checkmark$ Find the Consistency vector:

$$
\left(\begin{array}{l}
5,53 \\
5,40 \\
5,15 \\
5,07 \\
5,26
\end{array}\right)=\left(\begin{array}{c}
2,45 \\
1,57 \\
0,22 \\
0,40 \\
0,76
\end{array}\right) \times\left(\begin{array}{c}
\frac{1}{0,44} \\
\frac{1}{0,29} \\
\frac{1}{0,04} \\
\frac{1}{0,08} \\
\frac{1}{0,14}
\end{array}\right)
$$

$\checkmark$ Find $\lambda_{\max }$ and determinate CI and CR:

$$
\begin{aligned}
& \lambda_{\max }=\frac{5,53+5,40+5,15+5,07+5,26}{5}=5,28 \\
& C I=\frac{5,28-5}{4}=0,07 \\
& C R=\frac{0,07}{1,12}=0,06
\end{aligned}
$$

$\mathrm{CR}<0.1$ The consistency ratio is acceptable; the system is consistent.

\section{Alternatives weights:}

This is the final step of AHP. The goal is to get the weight of each ERP solution in order to choose the best ERP system, for each criterion, the matrix of ERP solution will be created, there are five criteria, that's why five matrixes are obtained.

following the same steps as before, the ERP weights are determined as shown below:

Table 6. Alternative's weight for Adaptability

\begin{tabular}{|c|c|c|c|}
\hline Alternatives & ERP A & ERP B & Weight \\
\hline ERP A & 1 & 5 & 0,83 \\
\hline ERP B & $1 / 5$ & 1 & 0,17 \\
\hline
\end{tabular}


Table 7. Alternative's weight for Financial:

\begin{tabular}{|c|c|c|c|}
\hline Alternatives & ERP A & ERP B & Weight \\
\hline ERP A & 1 & $1 / 5$ & 0,17 \\
\hline ERP B & 5 & 1 & 0,83 \\
\hline
\end{tabular}

Table 8. Alternative's weight for Simplicity:

\begin{tabular}{|c|c|c|c|}
\hline Alternatives & ERP A & ERP B & Weight \\
\hline ERP A & 1 & $1 / 3$ & 0,25 \\
\hline ERP B & 3 & 1 & 0,75 \\
\hline
\end{tabular}

Table 9. Alternative's weight for Provider services:

\begin{tabular}{|c|c|c|c|}
\hline Alternatives & ERP A & ERP B & Weight \\
\hline ERP A & 1 & 3 & 0,75 \\
\hline ERP B & $1 / 3$ & 1 & 0,25 \\
\hline
\end{tabular}

Table 10. Alternative's weight for Implementation approch:

\begin{tabular}{|c|c|c|c|}
\hline Alternatives & ERP A & ERP B & Weight \\
\hline ERP A & 1 & 7 & 0,88 \\
\hline ERP B & $1 / 7$ & 1 & 0,13 \\
\hline
\end{tabular}

The results (weights) are combined in this matrix:

Table 11. Matrix of weights:

\begin{tabular}{|c|l|l|l|l|l|}
\hline Alternatives & C1 & C2 & C3 & C4 & C5 \\
\hline ERP A & 0,83 & 0,17 & 0,25 & 0,75 & 0,88 \\
\hline ERP B & 0,17 & 0,83 & 0,75 & 0,25 & 0,13 \\
\hline
\end{tabular}

To obtain the last result the transpose of the matrix above is multiplied by the weight vector determined above (Table 4):

$$
\left(\begin{array}{l}
0,61 \\
0,38
\end{array}\right)=\left(\begin{array}{lllll}
0,83 & 0,17 & 0,25 & 0,75 & 0,88 \\
0,17 & 0,83 & 0,75 & 0,25 & 0,13
\end{array}\right)\left(\begin{array}{l}
0,44 \\
0,29 \\
0,04 \\
0,08 \\
0,14
\end{array}\right)
$$

We finally establish the weight of each ERP, 0.61 for ERP A and 0.38 for ERP B, based on the five criteria and the data we gathered, and by applying the AHP method, we can conclude that the ERP A is more suitable for the company compared to the ERP B.

\section{CONCLUSION \& DISCUSSIONS}

MCDMs are often used in ERP selection process, AHP is considered among the most popular methods for this type of treatments. the application of the AHP method starts with a problem modeling through a simple and clear hierarchy which allows its decomposition into three or four levels: selection of the ERP, criteria, sub-criteria whenever they exist, and alternative solutions (ERP).

The use of the AHP method requires firstly, the determination of the list of criteria that will be used to evaluate the ERP, then elaboration of a shortlist of alternatives ERP, and subsequently the weight of each criterion related to the others. AHP method uses pairwise comparison in order to determine the weights of the criteria and to evaluate the ERP systems (alternatives), these pairwise comparisons are performed by decision makers.

The pairwise comparison use a Saaty scale which show decision makers preferences and judgments among the following options: equal importance, moderate importance, strong importance, very strong importance, and absolute importance.

Decision makers could provide a paired comparison with a precision that depends on multiple elements such as their knowledge in the field of ERP, their experience in similar projects, and the understanding level of the needs of the company and its constraints.

Using AHP, does not guarantee finding the optimal solution, decision makers must understand details, strengths, and limitations of AHP method.

Even though the nine-pointe numerical scale has the advantages of simplicity and easiness for use, it does not take into account the uncertainty related to the preferences of decision makers. Indeed, some ERP selection criteria contain ambiguity and multiplicity of meaning (adaptability, simplicity...). Furthermore, the human assessment on qualitative attributes is generally subjective and thus imprecise. For this reason, in some cases, AHP seems inadequate to determine accurately the selection criteria weights.

Fuzzy concept can be incorporated with the pairwise comparison as an extension of AHP, in order to represent this kind of uncertainly related to decision makers judgments.

Thus, the triangular fuzzy numbers can be used to improve the nine-point scaling scheme and represent subjective pairwise comparisons of ERP selection criteria, hence the use of Fuzzy AHP method.

\section{REFERENCES}

[1] Moutaz Haddara and Ondrej Zach (2011). ERP Systems in SMEs: A Literature Review.

[2] Malhotra and Temponi. Critical decisions for ERP integration: Small business issues, International Journal of Information Management, Volume 30, Issue 1, February 2010, Pages 28-37.

[3] Huseyin Selcuk Kilic, Selim Zaim and Dursun Delen. Selecting "The Best" ERP system for SMEs using a combination of ANP and PROMETHEE methods, Expert Systems with Applications, Volume 42, Issue 5, 1 April 2015, Pages 2343-2352.

[4] Kilic, Zaim, and Delen. Development of a hybrid methodology for ERP system selection: The case of Turkish Airlines, Decision Support Systems Journal, Volume 66, October 2014, Pages 82-92.

[5] Gürbüz, Alptekin and Isıklar Alptekin. A hybrid MCDM methodology for ERP selection problem with interacting 
criteria, Decision Support Systems Journal, Volume 54, Issue 1, December 2012, Pages 206-214.

[6] Lin, Chen, Ting. An ERP model for supplier selection in electronics industry, Expert Systems with Applications Journal, Volume 38, Issue 3, March 2011, Pages 17601765 .

[7] Perçin. Using the ANP approach in selecting and benchmarking ERP systems, Benchmarking: An International Journal, Vol. 15 Issue: 5, pp.630-649 (2008)

[8] Sandarbh Shukla, Mishra, Rajeev Jain, Yadav. An integrated decision-making approach for ERP system selection using SWARA and PROMETHEE method, International Journal of Intelligent Enterprise, volume 3, Issue 2 (2016)

[9] Ayag and Özdemir. An intelligent approach to ERP software selection through fuzzy ANP, International Journal of Production Research, Volume 45, Pages 21692194, Issue 10, (2007).

[10] Wei, Chien and Wang. An AHP-based approach to ERP system selection, International Journal of Production Economics, Volume 96, Issue 1, 18 April 2005, Pages 47-62, (2005)

[11] Özdağoğlu and al. Comparison Of AHP And Fuzzy AHP For The Multi-Criteria Decision Making Processes With Linguistic Evaluations, 2007.

[12] Gunasekara, Ngai, and McGaughey. Information technology and systems justification: A review for research and applications, European Journal of Operational Research, Volume 173, Issue 3, 16 September 2006, Pages 957-983.

[13] Ünal and Güner. Selection of ERP suppliers using AHP tools in the clothing industry, International Journal of Clothing Science and Technology, Vol. 21 Issue: 4, (2009).
[14] Cebeci. Fuzzy AHP-based decision support system for selecting ERP systems in textile industry by using balanced score card, Expert Systems with Applications, Volume 36, Issue 5, July 2009, Pages 8900-8909

[15] C.Kahramane. Selection among ERP outsourcing alternatives using a fuzzy multi-criteria decision-making methodology, International Journal of Production Research, Volume 48, 2010 - Issue 2.

[16] Karsak, Özogul. An integrated decision-making approach for ERP system selection, Expert Systems with Applications, Volume 36, Issue 1, January 2009, Pages 660-667.

[17] Burak Efe. An integrated fuzzy multi criteria group decision making approach for ERP system selection, Applied Soft Computing, Volume 38, January 2016, Pages 106-117.

[18] Maria Manuela Cruz-Cunha. ERP Selection using an AHP-based Decision Support System, IRMJ journal, volume 29 , Issue 4 (2016).

[19] Moutaz Haddara. ERP Selection: The Smart Way, Procedia Technology, Volume 16, 2014, Pages 394-403.

[20] Igor Rivera and María del Rosario Pérez Salazar (2013). GUÍA DE SELECCIÓN DE ERP EN LAS PEQUEÑAS Y MEDIANAS EMPRESAS MEXICANAS

[21] Wen-Hsien Tsai, Pei-Ling Lee, Yu-Shan Shen and HsiuLing Lin (2013). A comprehensive study of the relationship between entrerprise resource planning selection criteria and enterprise resource planning success.

[22] Huseyin Selcuk Kilic, Selim Zaim and Dursun Delen. Selecting "The Best "ERP system for SMEs using a combination of ANP and PRPMETHEE methods. 